\title{
Pharmacokinetics, Safety and Tolerability of Rotigotine Transdermal Patch in Healthy Japanese and Caucasian Subjects
}

\author{
Willi Cawello $\cdot$ Seong R. Kim $\cdot$ Marina Braun $\cdot$ \\ Jan-Peer Elshoff $\cdot$ Junji Ikeda $\cdot$ Tomoo Funaki
}

Published online: 1 November 2013

(c) The Author(s) 2013. This article is published with open access at Springerlink.com

\begin{abstract}
Background and Objectives Rotigotine is a dopamine receptor agonist with activity across the $D_{1}$ through to $D_{5}$ receptors as well as select serotonergic and adrenergic sites; continuous transdermal delivery of rotigotine with replacement of the patch once daily maintains stable plasma concentrations over $24 \mathrm{~h}$. Rotigotine is indicated for the treatment of early and advanced-stage Parkinson's disease and moderate-to-severe idiopathic restless legs syndrome. The pharmacokinetics and pharmacodynamics of a drug may vary between subjects of different ethnic origin. This study evaluated the pharmacokinetics, safety, and tolerability of single-dose treatment with rotigotine transdermal patch in Japanese and Caucasian subjects.

Methods In this open-label, parallel-group study, healthy male and female subjects of Japanese or Caucasian ethnic origin were matched by sex, body mass index, and age. A single transdermal patch delivering $2 \mathrm{mg} / 24 \mathrm{~h}$ rotigotine (patch content $4.5 \mathrm{mg}$ ) was applied to the ventral/lateral abdomen for $24 \mathrm{~h}$. The main outcome measures were the plasma concentrations of unconjugated and total rotigotine and its desalkyl metabolites and derived pharmacokinetic parameters (area under the concentration-time curve from time zero to last quantifiable concentration $\left[\mathrm{AUC}_{\text {last }}\right]$, maximum plasma concentration $\left[C_{\max }\right]$, and body weightand dose-normalized values).
\end{abstract}

ClinicalTrials.gov registration number: NCT01761526.

W. Cawello $(\bowtie) \cdot$ M. Braun · J.-P. Elshoff

UCB Pharma, Alfred-Nobel-Str. 10,

40789 Monheim am Rhein, Germany

e-mail: Willi.Cawello@ucb.com

S. R. Kim · J. Ikeda $\cdot$ T. Funaki

Otsuka Pharmaceutical Co. Ltd., Tokyo, Japan
Results The pharmacokinetic analysis included 48 subjects (24 Japanese, 24 Caucasian). The mean apparent dose of rotigotine was $2.0 \pm 0.5 \mathrm{mg}$ for Japanese subjects and $2.08 \pm 0.58 \mathrm{mg}$ for Caucasians. Plasma concentrationtime profiles of unconjugated rotigotine and of the main metabolites were similar for both ethnic groups. Parameters of model-independent pharmacokinetics, $C_{\max }$, time to $C_{\max }\left(t_{\max }\right)$, and $\mathrm{AUC}_{\text {last }}$, for unconjugated rotigotine showed no statistically significant differences between Japanese and Caucasian subjects. Values of concentrationdependent pharmacokinetic parameters were higher in female subjects; this difference was minimized after correction for body weight. A statistically significant difference between ethnic groups was observed for total rotigotine concentrations (total rotigotine $=$ unconjugated rotigotine + conjugated rotigotine), with slightly lower values in Caucasians after correction for body weight and apparent dose. No relevant differences were observed between males and females. Inter-individual variability was high. The terminal half-life for unconjugated rotigotine was $5.3 \mathrm{~h}$ in Japanese subjects and $5.7 \mathrm{~h}$ in Caucasians; corresponding values for total rotigotine were $8.6 \mathrm{~h}$ and $9.6 \mathrm{~h}$. Less than $0.1 \%$ of the apparent dose was renally excreted as the parent compound. Renal elimination of total rotigotine covers $11.7 \%$ of absorbed dose in Japanese subjects and $10.8 \%$ of the absorbed dose in Caucasians, whereas the renal elimination via total despropyl rotigotine was 8.2 and $7.1 \%$, respectively. The corresponding values for total desthienylethyl rotigotine were $3.5 \%$ in Japanese subjects and $4.2 \%$ Caucasians. Most adverse events were mild in intensity and typical for dopamine agonists or for transdermal therapeutics.

Conclusion Administration of a single patch delivering $2 \mathrm{mg} / 24 \mathrm{~h}$ rotigotine resulted in comparable pharmacokinetic profiles in Japanese and Caucasian subjects. The 
rotigotine transdermal patch was generally well-tolerated. Our findings suggest similar dose requirements for Japanese and Caucasian populations.

\section{Introduction}

Parkinson's disease (PD) is the most common neurodegenerative disease after Alzheimer's disease [1]. Treatment of PD is complex due to the progressive nature and array of motor and non-motor features of the disease, and the early and late side effects associated with therapeutic interventions [2]. Levodopa is still the most potent symptomatic drug for PD [3]; however, guidelines recommend initial treatment with a dopamine receptor agonist (particularly in young-onset patients) to avoid the development of motor complications associated with long-term levodopa use [4, 5]. Dopamine receptor agonists are also recommended as the first-line treatment for patients with moderate-to-severe idiopathic restless legs syndrome (RLS) [6].

Rotigotine, the levorotatory enantiomer of racemic aminotetralin, is a novel non-ergolinic dopamine receptor agonist with preferential binding to $\mathrm{D}_{3}, \mathrm{D}_{2}$, and $\mathrm{D}_{1}$ receptor subtypes [7]. Rotigotine has been incorporated into a silicone-based transdermal patch that provides continuous drug delivery and stable plasma concentrations when the patch is replaced once every $24 \mathrm{~h}$ [8]. Following application, approximately half of the administered rotigotine dose (46\%) is systemically absorbed [9]. Rotigotine is rapidly metabolized, mainly by conjugation (sulfation and glucuronidation) [10]. The terminal elimination half-life $\left(t_{1 / 2}\right)$ of unconjugated rotigotine is $5.4 \mathrm{~h} \mathrm{[10]}$ and of conjugated

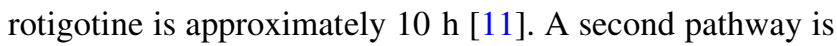
the formation of inactive $N$-desalkyl metabolites with subsequent conjugation [9]. Efficacy of rotigotine in the treatment of early PD [12-14], advanced PD [15-17], and RLS [18-20] has been demonstrated in randomized placebo-controlled trials and rotigotine is approved for the treatment of PD and RLS in Europe and the USA.

The efficacy and tolerability of rotigotine have mainly been investigated in Caucasian subjects. Various factors including differences in height, body weight, genetic polymorphism in drug-metabolizing enzymes such as cytochrome P450 (CYP) 2C19 and CYP2C9, and enzyme, transporter and receptor saturation, may influence pharmacokinetics and pharmacodynamics of rotigotine in subjects of different ethnic origin [21]. The route of administration also plays a role and ethnic differences may not be relevant if the drug is applied transdermally [22]. Many physicians prescribe medications at lower doses when treating Asian patients with PD [23]. For example, subtherapeutic doses of the dopamine receptor agonist pergolide are commonly used in clinical practice in Japan; although doses of up to $1.25 \mathrm{mg} /$ day are recommended for Japanese patients, many receive just $0.6 \mathrm{mg} /$ day [24]. It is important that potential pharmacokinetic differences are considered when determining dose adjustments for different ethnic groups. To compare the pharmacokinetics and safety of rotigotine in subjects of different ethnic origin, the administration of a single transdermal patch (delivering $2 \mathrm{mg} / 24 \mathrm{~h}$ ) in healthy Japanese and Caucasian subjects was investigated in this open-label phase I clinical study (NCT01761526).

\section{Subjects and Methods}

\subsection{Study Population and Design}

This open-label, non-randomized, single-dose, parallelgroup study was carried out at FOCUS Clinical Drug Development GmbH, Neuss, Germany in 2002. Healthy male and female subjects of Japanese or Caucasian ethnic origin were eligible to participate if they were aged $20-45$ years, had a body mass index (BMI) of $18-28 \mathrm{~kg} /$ $\mathrm{m}^{2}$, were willing and able to comply with all study requirements, and were healthy according to eligibility assessments (without any clinically relevant deviations from normal). Japanese participants were required to have been born in Japan to parents of $100 \%$ Japanese origin, and to have left Japan no more than 10 years before the start of the study.

Exclusion criteria included a clinically relevant allergy; known or suspected drug hypersensitivity (in particular to any components of the trial medication); prior or current clinically relevant medical or psychiatric conditions; a history of chronic alcohol or drug abuse; positive testing for alcohol or drugs, HIV-1/HIV-2 antibodies, hepatitis B surface antigen, or hepatitis $\mathrm{C}$ virus antibody; and blood donation or comparable blood loss of $>350 \mathrm{~mL}$ within 3 months prior to patch application. In addition, no acute diseases, skin diseases, suspicious and undiagnosed skin lesions, skin tumors, history of significant hypersensitivity to adhesives or other transdermal products, or recent unresolved contact dermatitis were allowed. Individuals were also excluded if they had participated in a clinical trial of an investigational product within 3 months prior to patch application; had used any concomitant medication (excluding paracetamol) within 2 weeks prior to patch application; had used methylphenidate, amphetamines, or catechol- $O$-methyltransferase inhibitors within 28 days prior to patch application; or had used monoamine oxidase inhibitors, reserpine, alpha-methyldopa, antipsychotic agents, antipsychotics, clozapine, olanzapine, flunarizine, cinnarizine, metoclopramide, risperidone, or quetiapine or any other known enzyme-inducing or inhibiting agent 
within 3 months prior to patch application. More than 5 cigarettes/day, $600 \mathrm{mg}$ caffeine/day, and/or $20 \mathrm{~g}$ alcohol/ day, a diet deviating notably from normal daily amounts of proteins, carbohydrates or fat, or heavy physical exertion 2 days before the eligibility assessment also led to exclusion. Female subjects were excluded if they were without medically adequate contraception, were pregnant or lactating, or had taken oral contraceptives or hormone replacement within 4 weeks prior to the eligibility assessment. Caucasian and Japanese subjects were matched by sex, BMI $( \pm 10 \%)$, and age ( \pm 5 years). The study was conducted in accordance with Good Clinical Practice and the Declaration of Helsinki. The protocol and amendments were approved by the Ethics Committee of the 'Ärztekammer Nordrhein', Düsseldorf, Germany. Written informed consent was obtained from all participants.

Eligibility assessments (medical history, complete physical examination, 12-lead ECG, vital signs and laboratory screening, alcohol/drug screening and serology, and pregnancy test) were conducted within 21 days before patch application. Eligibility was confirmed on Day -1 (day before patch application) with a repeat of the physical examination, vital signs, ECG, pregnancy test, and alcohol/ drug screening. Eligible subjects were hospitalized on the day of patch application for a period of $60 \mathrm{~h}$. One $10 \mathrm{~cm}^{2}$ patch containing $4.5 \mathrm{mg}$ rotigotine $(2 \mathrm{mg} / 24 \mathrm{~h}$ delivery) (UCB Pharma, Monheim am Rhein, Germany) was applied to the ventral/lateral abdomen in the morning and removed after $24 \mathrm{~h}$. Subjects stayed in bed for at least $2 \mathrm{~h}$ after patch application. A follow-up visit was conducted within 5-10 days.

\subsection{Sample Collection and Analytical Methods}

Blood samples for the pharmacokinetic assessment of rotigotine and metabolites in plasma were collected into lithium-heparinized monovettes prior to patch application
(0 h) and at 1, 2, 4, 8, 12, 16, 24, 25, 26, 28, 30, 33, 36, 48, and $60 \mathrm{~h}$ after patch application. Assessments included both unconjugated and total rotigotine (total rotigotine $=$ unconjugated rotigotine + conjugated rotigotine), and the metabolites despropyl and desthienylethyl rotigotine. Samples were assayed untreated and after pre-incubation with glucuronidase to convert glucuronide and sulfate conjugates back into the unconjugated moiety for total rotigotine determination. Concentrations of rotigotine and metabolites in plasma were determined by liquid chromatography with tandem mass spectrometry (LC-MS/ MS) using Positive Electrospray Ionization (ESI) and Selected Reaction Monitoring (SRM) with the following lower limits of quantification (LLQ): $0.01 \mathrm{ng} / \mathrm{mL}$ for unconjugated rotigotine, $0.01 \mathrm{ng} / \mathrm{mL}$ for total rotigotine, $0.1 \mathrm{ng} / \mathrm{mL}$ for total despropyl rotigotine, and $0.1 \mathrm{ng} / \mathrm{mL}$ for total desthienylethyl rotigotine. Internal standards were fentanyl citrate (Promochem, Wesel, Germany) for assay of unconjugated and total rotigotine and $\mathrm{N}$-despropyl-propafenone oxalate for assay of the desalkyl metabolites. Standard curves were linear within the calibration range $0.01-2.0 \mathrm{ng} / \mathrm{mL}$ for unconjugated and total rotigotine, and $0.1-10 \mathrm{ng} / \mathrm{mL}$ for the metabolites. Overall accuracy and precision for calibration standards and quality controls were well within $10 \%$ at all concentrations.

For the evaluation of renal excretion of rotigotine and its metabolites, urine was collected pre-dose and 0-24, 24-48, and $48-60 \mathrm{~h}$ after patch application. Urine samples were analyzed by LC-MS/MS with the following LLQs: $0.05 \mathrm{ng} / \mathrm{mL}$ for unconjugated rotigotine, $0.1 \mathrm{ng} / \mathrm{mL}$ for unconjugated despropyl rotigotine, $0.25 \mathrm{ng} / \mathrm{mL}$ for unconjugated desthienylethyl rotigotine, and $0.5 \mathrm{ng} / \mathrm{mL}$ for total despropyl rotigotine, total desthienylethyl rotigotine, and total rotigotine. Standard curves were linear within the calibration range of $0.05-2.0 \mathrm{ng} / \mathrm{mL}$ for unconjugated rotigotine, $0.1-10 \mathrm{ng} / \mathrm{mL}$ for unconjugated desthienylethyl rotigotine, and $0.5-30 \mathrm{ng} / \mathrm{mL}$ for total rotigotine and total

Table 1 Demographic characteristics of the per-protocol population

\begin{tabular}{|c|c|c|c|c|c|}
\hline \multirow[t]{2}{*}{ Sex } & \multirow[t]{2}{*}{ Parameter } & \multicolumn{2}{|c|}{ Japanese $(n=24)$} & \multicolumn{2}{|c|}{ Caucasian $(n=24)$} \\
\hline & & Mean (SD) & Range & Mean (SD) & Range \\
\hline \multirow[t]{4}{*}{ Female $(n=12)$} & Age (years) & $32.3(5.9)$ & $23-41$ & $31.7(5.8)$ & $23-41$ \\
\hline & BMI $\left(\mathrm{kg} / \mathrm{m}^{2}\right)$ & $21.2(2.0)$ & $19-25$ & $20.7(1.3)$ & $19-23$ \\
\hline & Height (m) & $1.58(0.06)$ & $1.50-1.72$ & $1.67(0.08)$ & $1.60-1.81$ \\
\hline & Weight (kg) & $53.3(8.4)$ & $44-75$ & $58.0(5.7)$ & $49-68$ \\
\hline \multirow[t]{4}{*}{ Male $(n=12)$} & Age (years) & $28.9(7.7)$ & $20-44$ & $28.9(6.0)$ & $20-40$ \\
\hline & BMI $\left(\mathrm{kg} / \mathrm{m}^{2}\right)$ & $21.0(1.2)$ & $20-24$ & $21.2(1.8)$ & $19-24$ \\
\hline & Height (m) & $1.73(0.04)$ & $1.65-1.77$ & $1.79(0.05)$ & $1.68-1.85$ \\
\hline & Weight (kg) & $62.4(4.4)$ & $56-74$ & $68.3(6.5)$ & $57-78$ \\
\hline
\end{tabular}

Data are expressed as arithmetic means (SD) and range

$B M I$ body mass index, $S D$ standard deviation 
despropyl and desthienylethyl rotigotine. In order to evaluate the apparent dose, the patches were analyzed for residual drug content after the $24-\mathrm{h}$ patch-on period.

\subsection{Pharmacokinetic Analysis}

Primary pharmacokinetic variables were the plasma concentrations of unconjugated and total rotigotine and its desalkyl metabolites and derived pharmacokinetic parameters [area under the concentration-time curve (AUC) from time zero to last quantifiable concentration $\left(\mathrm{AUC}_{\text {last }}\right)$, maximum plasma concentration $\left(C_{\max }\right)$, and body weight- and dose-normalized values]. $\mathrm{AUC}_{\text {last }}$ was calculated using the $\log /$ linear trapezoidal rule (linear up to $C_{\max }$ and $\log$ thereafter).

Secondary parameters included time to $C_{\max }\left(t_{\max }\right), t_{1 / 2}$, AUC from time zero to infinity $\left(\mathrm{AUC}_{\infty}\right)$, total body

Table 2 Descriptive statistics of derived pharmacokinetic parameters for unconjugated rotigotine and total rotigotine

\begin{tabular}{|c|c|c|c|c|}
\hline \multirow[t]{2}{*}{ Parameter } & \multicolumn{2}{|l|}{ Caucasian } & \multicolumn{2}{|l|}{ Japanese } \\
\hline & Female $(n=12)$ & Male $(n=12)$ & Female $(n=12)$ & Male $(n=12)$ \\
\hline \multicolumn{5}{|l|}{ Unconjugated rotigotine } \\
\hline Apparent dose $\mathrm{a}^{\mathrm{a}}(\mathrm{mg})$ & $2.28(24.1)$ & $1.88(29.8)$ & $2.03(26.1)$ & $1.97(25.4)$ \\
\hline $\mathrm{AUC}_{\text {last }}(\mathrm{ng} \cdot \mathrm{h} / \mathrm{mL})$ & $4.45(85.1)$ & $3.54(56.7)$ & $5.69(40.0)$ & $3.38(54.6)$ \\
\hline $\mathrm{AUC}_{\infty}(\mathrm{ng} \cdot \mathrm{h} / \mathrm{mL})$ & $4.74(87.1)^{\mathrm{c}}$ & $3.70(54.9)$ & $5.84(39.4)$ & $3.54(51.9)$ \\
\hline $\mathrm{AUC}_{\text {last,normBW }}(\mathrm{ng} \cdot \mathrm{h} \cdot \mathrm{kg} / \mathrm{mL})$ & $257(81.4)$ & $241(56.4)$ & $300(48.5)$ & $210(51.0)$ \\
\hline $\mathrm{AUC}_{\text {last,normBW,dose }}(\mathrm{ng} \cdot \mathrm{h} \cdot \mathrm{kg} / \mathrm{mL} / \mathrm{mg})$ & $115(63.9)$ & $133(38.5)$ & $152(29.8)$ & $111(32.2)$ \\
\hline$C_{\max }(\mathrm{ng} / \mathrm{mL})$ & $0.232(76.3)$ & $0.169(55.1)$ & $0.292(36.2)$ & $0.174(58.8)$ \\
\hline$C_{\max , \text { normBW }}(\mathrm{ng} \cdot \mathrm{kg} / \mathrm{mL})$ & $13.4(73.2)$ & $11.5(54.8)$ & $15.4(46.0)$ & $10.8(55.7)$ \\
\hline$C_{\text {max,normBW,dose }}(\mathrm{ng} \cdot \mathrm{kg} / \mathrm{mL} / \mathrm{mg})$ & $6.02(57.0)$ & $6.35(39.6)$ & $7.81(31.1)$ & $5.68(38.4)$ \\
\hline$t_{\max }^{\mathrm{b}}(\mathrm{h})$ & $16(8-25)$ & $16(8-26)$ & $16(12-25)$ & $16(12-24)$ \\
\hline$t_{1 / 2}^{\mathrm{a}}(\mathrm{h})$ & $5.82(44.6)^{\mathrm{c}}$ & $5.62(32.6)$ & $5.52(44.7)$ & $5.15(49.0)$ \\
\hline$V_{\mathrm{d}}^{\mathrm{a}}(\mathrm{L})$ & $4,337(65.2)^{\mathrm{c}}$ & $4,157(44.0)$ & $2,624(35.8)$ & $3,942(38.9)$ \\
\hline$A_{\mathrm{e}}^{\mathrm{a}}(\mu \mathrm{g})$ & $1.074(53.4)^{\mathrm{d}}$ & $0.93(43.6)$ & $1.30(65.8)$ & $1.11(51.8)$ \\
\hline$f_{\mathrm{e}}(\%$ of apparent dose $)$ & $0.046(58.7)^{\mathrm{d}}$ & $0.055(62.5)$ & $0.061(48.1)$ & $0.058(48.7)$ \\
\hline $\mathrm{CL}^{\mathrm{a}}(\mathrm{L} / \mathrm{h})$ & $558(55.6)^{\mathrm{d}}$ & $524.2(38.1)$ & $349.0(32.2)$ & $565.0(34.9)$ \\
\hline $\mathrm{CL}_{\text {normBW,dose }}{ }^{\mathrm{a}}(\mathrm{L} \cdot \mathrm{mg} / \mathrm{h} / \mathrm{kg})$ & $4.60(45.5)^{\mathrm{d}}$ & $3.093(36.2)$ & $2.904(30.9)$ & $3.899(38.9)$ \\
\hline $\mathrm{CL}_{\mathrm{R}}^{\mathrm{a}}(\mathrm{L} / \mathrm{h})$ & $0.227(77.9)$ & $0.2648(51.1)$ & $0.1979(47.1)$ & $0.3426(64.2)$ \\
\hline \multicolumn{5}{|l|}{ Total rotigotine } \\
\hline $\mathrm{AUC}_{\text {last }}(\mathrm{ng} \cdot \mathrm{h} / \mathrm{mL})$ & $27.3(65.4)$ & $25.1(35.1)$ & $37.4(28.6)$ & $31.9(41.9)$ \\
\hline $\mathrm{AUC}_{\infty}(\mathrm{ng} \cdot \mathrm{h} / \mathrm{mL})$ & $28.1(65.5)$ & $25.6(34.5)$ & $38.5(27.0)$ & $32.3(41.4)$ \\
\hline $\mathrm{AUC}_{\text {last,normBW }}(\mathrm{ng} \cdot \mathrm{h} \cdot \mathrm{kg} / \mathrm{mL})$ & $1,578(69.1)$ & $1,704(37.2)$ & $1,972(36.8)$ & $1,986(39.4)$ \\
\hline $\mathrm{AUC}_{\text {last,normBW,dose }}(\mathrm{ng} \cdot \mathrm{h} \cdot \mathrm{kg} / \mathrm{mL} / \mathrm{mg})$ & 709 (50.6) & $942(26.7)$ & $1,003(17.8)$ & $1,045(21.3)$ \\
\hline$C_{\max }(\mathrm{ng} / \mathrm{mL})$ & $1.24(57.3)$ & $1.13(38.6)$ & $1.73(33.6)$ & $1.52(48.0)$ \\
\hline$C_{\max , \text { normBW }}(\mathrm{ng} \cdot \mathrm{kg} / \mathrm{mL})$ & $71.8(60.1)$ & $76.7(40.1)$ & $91.4(43.1)$ & $94.7(45.6)$ \\
\hline$C_{\text {max,normBW,dose }}(\mathrm{ng} \cdot \mathrm{kg} / \mathrm{mL} / \mathrm{mg})$ & $32.2(43.3)$ & $42.4(26.9)$ & $46.5(28.3)$ & $49.8(27.5)$ \\
\hline$t_{\max }^{\mathrm{b}}(\mathrm{h})$ & $16(12-26)$ & $16(8-26)$ & $16(16-28)$ & $16(8-25)$ \\
\hline$t_{1 / 2}^{\mathrm{a}}(\mathrm{h})$ & $10.0(21.0)$ & $9.14(18.9)$ & $9.42(21.2)$ & $7.87(16.4)$ \\
\hline$A_{\mathrm{e}}^{\mathrm{a}}(\mu \mathrm{g})$ & $256(46.4)^{\mathrm{d}}$ & $213(59.2)$ & $257(62.7)$ & $231(53.2)$ \\
\hline$f_{\mathrm{e}}(\%$ of apparent dose $)$ & $10.5(31.1)^{\mathrm{d}}$ & $11.1(40.4)$ & $11.9(45.5)$ & $11.6(43.2)$ \\
\hline $\mathrm{CL}_{\mathrm{R}}^{\mathrm{a}}(\mathrm{L} / \mathrm{h})$ & $8.19(49.9)^{\mathrm{d}}$ & $7.93(38.1)$ & $6.17(44.4)$ & $7.42(70.1)$ \\
\hline
\end{tabular}

Data are expressed as geometric mean (CV\%) unless stated otherwise

$A_{e}$ amount excreted into urine, $A U C_{\infty}$ area under the plasma concentration-time curve from time zero to infinity, $A U C_{\text {last }}$ area under the plasma concentration-time curve from time zero to last quantifiable concentration, $C L$ total body clearance, $C L_{R}$ renal clearance, $C_{\text {max }}$ maximum plasma concentration, $C V \%$ percentage coefficient of variation, $f_{e}$ fraction excreted into urine, norm $B W$ normalized by body weight, norm $B W$, dose normalized by body weight and dose, $t_{1 / 2}$ elimination half-life, $t_{\max }$ time to $C_{\max }, V_{d}$ apparent volume of distribution

a Arithmetic mean (CV\%)

b Median (range)

c $n=11$

${ }^{\mathrm{d}} n=10$ 
clearance (CL), and apparent volume of distribution $\left(V_{\mathrm{d}}\right)$. Urine concentrations of rotigotine (unconjugated and total) and its despropyl and desthienylethyl metabolites (unconjugated and total) were also determined. Derived parameters included amount excreted into urine $\left(A_{\mathrm{e}}\right)$, fraction excreted into urine (\% of applied and apparent dose; $f_{\mathrm{e}}$ ), and renal clearance $\left(\mathrm{CL}_{\mathrm{R}}\right)$. $\mathrm{AUC}_{\infty}$ was calculated as $\mathrm{AUC}_{\text {last }}+C_{\text {last }} / \lambda_{\mathrm{z}}$, where $C_{\text {last }}$ is the last quantifiable concentration and $\lambda_{\mathrm{z}}$ the terminal rate constant. $\lambda_{\mathrm{z}}$ was estimated by log-linear regression analysis on data points visually assessed to be in the terminal log-linear phase. $t_{1 / 2}$ was calculated as $t_{1 / 2}=0.693 / \lambda_{\mathrm{z}}$. All concentrationdependent pharmacokinetic parameters were normalized by body weight as well as by apparent dose.

\subsection{Safety and Tolerability}

Vital signs and ECG measurements were performed repeatedly. A complete physical examination and safety laboratory assessments were carried out during the study and at follow-up. Adverse events (AEs) were monitored and recorded continuously. Skin tolerability was assessed pre-dose, directly after patch removal, and 3 and $24 \mathrm{~h}$ after patch removal according to classification scores for erythema [no reddening (0), slight reddening (1), evident reddening (2), papular reaction (3), vesiculation (4)] and for edema at the application site [no visible reaction (0), edema marginal (1), slight (2), evident (3), severe (4)]. Patch adhesiveness was assessed immediately prior to removing the patch using a score from 0 (no lift) to 5 (80-100\% lift).

\subsection{Statistical Analyses}

Pharmacokinetic analyses were performed using the perprotocol population, which included subjects who completed the study without any important protocol deviations and for whom primary parameter data were available. Descriptive statistics were displayed for the primary parameters $\mathrm{AUC}_{\text {last }}, C_{\max }$, and normalized values by ethnic group, sex, and overall. Data points below LLQ were substituted by zero for the calculation of mean values. The log-transformed primary parameters were submitted to an analysis of variance (ANOVA) with ethnic group and sex as fixed effects. The ANOVA was calculated utilizing general linear models (PROC GLM). The resulting estimated differences and corresponding $90 \%$ confidence intervals (CIs) were backtransformed to the original scale to calculate ratios (Japanese vs. Caucasian) and corresponding CIs. Lack of difference between ethnic groups was concluded if the $90 \%$ CIs for the ratios were fully contained within the
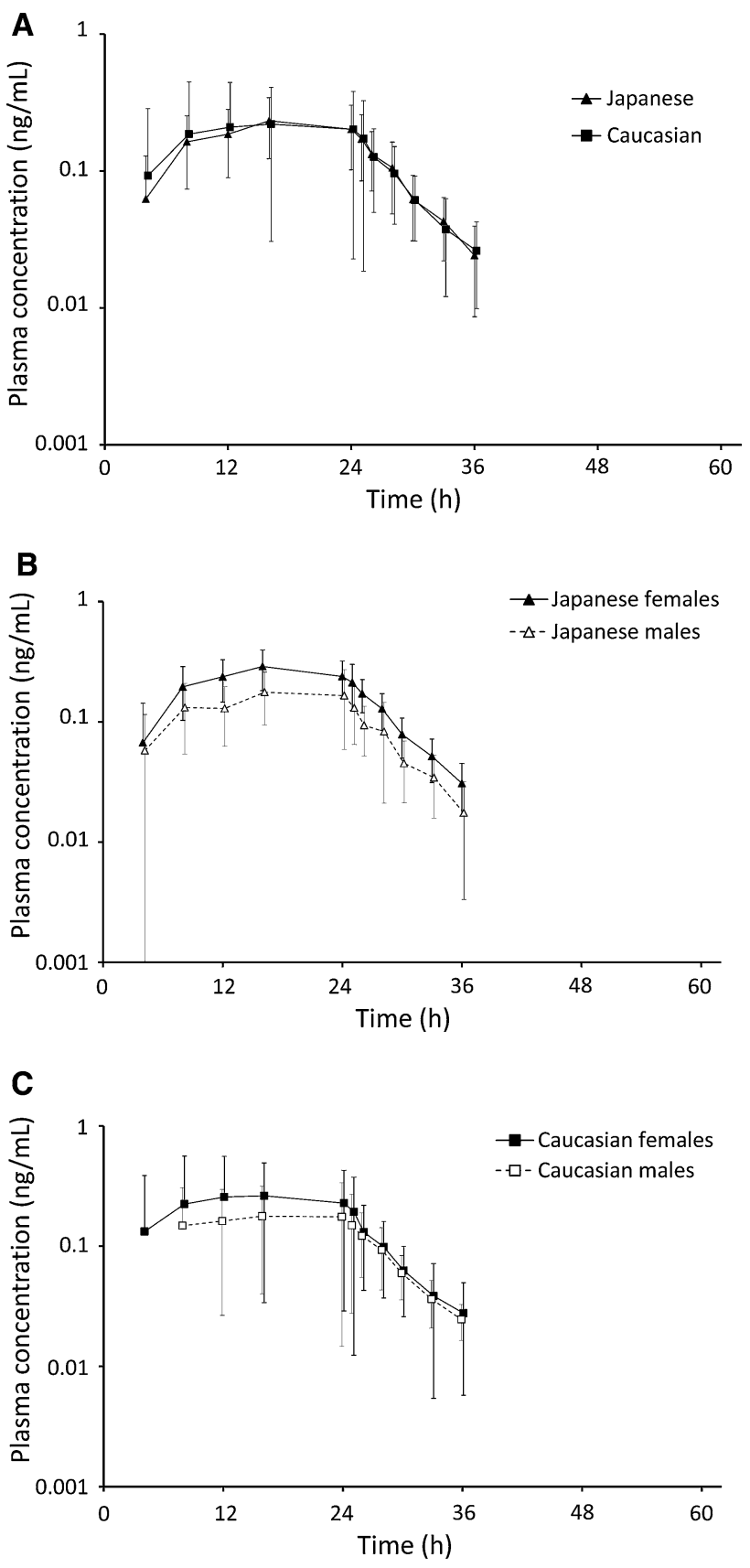

Fig. 1 Mean plasma concentrations (standard deviation) of unconjugated rotigotine in Japanese and Caucasian subjects; log-linear scale. a All subjects; b Japanese subjects by sex; c Caucasian subjects by sex

acceptance ranges for $\mathrm{AUC}_{\text {last }}(80-125)$ and for $C_{\max }$ (70-143), preferably with unity $(100 \%)$ included. Descriptive statistics were displayed for the secondary pharmacokinetic parameters without a formal statistical comparison between groups. All statistical evaluations were performed using $\mathrm{SAS}^{\circledR}$ software (version 8.2; SAS Institute, Cary, NC, USA).

All subjects were included in the safety analysis. AEs were coded using the dictionaries WHO Adverse Reactions 
Terminology (Schwarz Biosciences, version 1993) and MedDRA $^{\circledR}$ (Medical Dictionary for Regulatory Activities; version 5.1). A recurrent AE (e.g., headache for a couple of hours every day) was counted as multiple AEs. Safety and tolerability data were summarized descriptively.

\section{Results}

\subsection{Subject Demographics}

Fifty subjects were enrolled and received study medication. Two female Caucasian subjects were withdrawn due to AEs, leaving 48 subjects for the pharmacokinetic analysis, with 12 males and 12 females in each ethnic group. Demographic characteristics of the per-protocol population were similar for both ethnic groups, with mean body weight among Caucasians $10 \%$ higher than among Japanese subjects (Table 1). All subjects were judged to be healthy based on their medical histories, physical examination, and laboratory results.

\subsection{Pharmacokinetics of Unconjugated Rotigotine}

The mean apparent dose of rotigotine was $2.0 \pm 0.5 \mathrm{mg}$ for Japanese and $2.08 \pm 0.58 \mathrm{mg}$ for Caucasian subjects (accounting for approximately 44 and $46 \%$ of the total drug content of the patch, respectively). A large interindividual variability (overall range $0.94-3.46 \mathrm{mg}$ ) was observed, with a tendency towards slightly higher absorption in female subjects (Table 2).
Mean plasma concentration-time profiles of unconjugated rotigotine were similar in Japanese and Caucasian subjects following application of a single $4.5 \mathrm{mg}$ patch (Fig. 1). In both ethnic groups, values were higher in female than in male subjects. After a lag-time of $2-4 \mathrm{~h}$, plasma concentrations increased and reached a plateau after $8 \mathrm{~h}$ that was maintained until patch removal. $C_{\max }$ was reached after approximately $16 \mathrm{~h}$ among male and female subjects in both ethnic groups. Following patch removal, plasma concentrations declined rapidly with a $t_{1 / 2}$ of approximately 5-6 h, and were below LLQ $12 \mathrm{~h}$ after patch removal.

Table 2 summarizes the pharmacokinetic parameters for unconjugated rotigotine. Variability between subjects was high in both ethnic groups. Among the Caucasian subjects, very high $C_{\max }$ values were observed in one female ( 5 times the mean value) and one male (4 times the mean value); these individuals also had the highest apparent dose values. Statistical comparison for $C_{\max }$ and $\mathrm{AUC}_{\text {last }}$ for unconjugated rotigotine indicated no significant differences between the two ethnic groups with unity (1) included in the CI ranges (Table 3). Ratios were 1.14 for $C_{\max }$ and 1.10 for $\mathrm{AUC}_{\text {last }}$ without normalization. For both parameters, the differences between groups were minimized by normalization for body weight and increased by normalization for apparent dose (Table 3). Normalization for both factors resulted in a ratio for Japanese versus Caucasians of 1.08 (95\% CI 0.88-1.32) for $C_{\max }$ and of 1.05 (95\% CI 0.85-1.28) for $\mathrm{AUC}_{\text {last }}$ (Table 3). In both ethnic groups, females showed higher $\mathrm{AUC}_{\text {last }}$ and $C_{\max }$ values than males. This difference was

Table 3 Statistical comparison [point estimates (90\% CIs)]

\begin{tabular}{lllll}
\hline Comparison & Compound & Normalization & AUC $_{\text {last }}$ & $C_{\text {max }}$ \\
\hline Japanese vs. Caucasian & Unconjugated rotigotine & None & $1.10(0.84-1.44)$ & $1.14(0.88-1.47)$ \\
& & Body weight & $1.01(0.77-1.32)$ & $1.04(0.8-1.35)$ \\
& & Apparent dose & $1.15(0.93-1.42)$ & $1.18(0.96-1.45)$ \\
& Total rotigotine & Body weight + apparent dose & $1.05(0.85-1.28)$ & $1.08(0.88-1.32)$ \\
& & None & $1.32(1.08-1.62)$ & $1.37(1.12-1.68)$ \\
& & Body weight & $1.21(0.98-1.49)$ & $1.25(1.01-1.56)$ \\
Male vs. female & Apparent dose & $1.37(1.18-1.59)$ & $1.42(1.23-1.65)$ \\
& Unconjugated rotigotine & Body weight + apparent dose & $1.25(1.08-1.45)$ & $1.30(1.12-1.52)$ \\
& & Bone & $0.69(0.53-0.90)$ & $0.66(0.51-0.85)$ \\
& & Apparent dose & $0.81(0.62-1.06)$ & $0.78(0.60-1.01)$ \\
& Total rotigotine & Body weight + apparent dose & $0.78(0.63,0.96)$ & $0.74(0.60,0.91)$ \\
& & None & $0.91(0.75-1.12)$ & $0.88(0.72-1.07)$ \\
& & Body weight & $0.88(0.72-1.08)$ & $0.89(0.73-1.10)$ \\
& & Apparent dose & $1.04(0.84-1.29)$ & $1.05(0.85-1.31)$ \\
& & Body weight + apparent dose & $1.18(1.01-1.37)$ & $1.19(1.02-1.38)$ \\
\hline
\end{tabular}

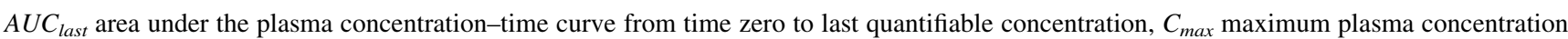


minimized after normalization by body weight and apparent dose (Tables 2, 3).

Terminal $t_{1 / 2}$ values of unconjugated rotigotine were similar between ethnic groups and between subjects of each sex. The renal elimination of unconjugated rotigotine was $\sim 1 \mu \mathrm{g}$ for all subgroups. The $V_{\mathrm{d}}$ was higher in Caucasians $(4,243 \mathrm{~L} \pm 54.3 \%)$ than in Japanese subjects (3,283 L $\pm 43.1 \%)$.

\subsection{Pharmacokinetics of Total Rotigotine}

Mean plasma concentrations of total rotigotine were lower in Caucasians than Japanese subjects, and were slightly higher in female subjects than in male subjects (Fig. 2). High inter-individual variability was observed. In both ethnic groups, plasma concentrations of total rotigotine reached mean maximum values after $16 \mathrm{~h}$ without developing a clear plateau phase. $C_{\max }$ and $\mathrm{AUC}_{\text {last }}$ were higher in Japanese subjects (Table 3); lower geometric means of $C_{\max }\left(27 \%\right.$ lower) and of $\mathrm{AUC}_{\text {last }}(24 \%$ lower $)$ were observed in Caucasian subjects. These differences were reduced following corrections for body weight and apparent dose $\left(C_{\max } 23 \%, \mathrm{AUC}_{\text {last }} 20 \%\right)$ and for body weight alone $\left(C_{\max } 20 \%, \mathrm{AUC}_{\text {last }} 17 \%\right)$. Statistical comparison between the two ethnic groups for these parameters indicated a difference as the $90 \%$ CIs did not include unity. Normalization by body weight reduced the ratios for both parameters and included unity for $\mathrm{AUC}_{\text {last }}$, whereas normalization by apparent dose had no effect on the ratios. Statistical analysis showed no relevant differences in $\mathrm{AUC}_{\text {last }}$ and $C_{\max }$ values between male and female subjects (Table 3).

\subsection{Pharmacokinetics of Despropyl and Desthienylethyl Rotigotine and its Conjugates}

Mean values of parameters for model-independent pharmacokinetics of the metabolites total despropyl rotigotine and total desthienylethyl rotigotine are shown in Table 4. Terminal $t_{1 / 2}$ could not be calculated owing to an insufficient number of samples above LLQ. Plasma concentration-time curves are shown for Japanese and Caucasian subjects in Fig. 3.

\subsection{Renal Elimination of All Measured Compounds}

In both ethnic groups, approximately $20 \%$ of the absorbed rotigotine dose was excreted into urine over $60 \mathrm{~h}$ after application of patch. Rotigotine was excreted as unconjugated rotigotine $(<1 \%$; Table 2$)$, total rotigotine (11.7 and $10.8 \%$ for Japanese and Caucasian subjects; Table 2), total despropyl rotigotine (8.2 and $7.1 \%$; Table 4), and total desthienylethyl rotigotine (3.5 and $4.2 \%$; Table 4).
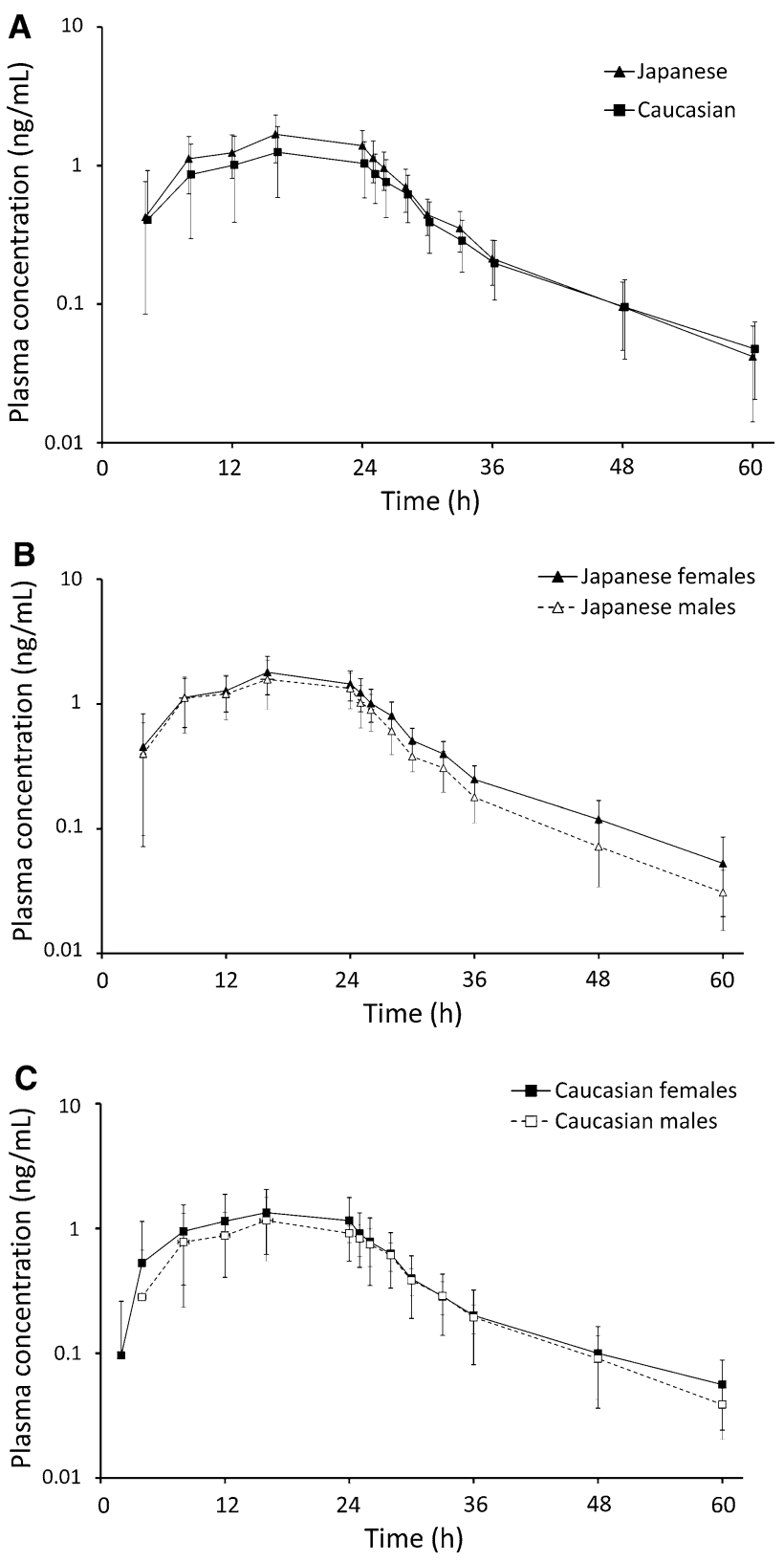

Fig. 2 Mean plasma concentrations (standard deviation) of total rotigotine in Japanese and Caucasian subjects; log-linear scale. a All subjects; b Japanese subjects by sex; c Caucasian subjects by sex

Unconjugated metabolites were not present or were below LLQ. The $C L_{R}$ of unconjugated rotigotine was similar in both groups, with a trend towards lower renal elimination of total rotigotine in Japanese subjects than in Caucasians (Table 2). The profile of renal elimination is shown in Fig. 4.

\subsection{Safety}

A total of 185 AEs were reported, of which 96 (52\%) occurred in Caucasians and $89(48 \%)$ occurred in 
Table 4 Pharmacokinetic parameters of total despropyl rotigotine and total desthienylethyl rotigotine after a single dose administration of a $4.5 \mathrm{mg}$ rotigotine patch (delivering $2 \mathrm{mg} / 24 \mathrm{~h}$ rotigotine) in Japanese and Caucasian subjects

\begin{tabular}{|c|c|c|c|c|}
\hline \multirow[t]{2}{*}{ Parameter } & \multicolumn{2}{|c|}{ Total despropyl rotigotine } & \multicolumn{2}{|c|}{ Total desthienylethyl rotigotine } \\
\hline & Japanese $(n=24)$ & Caucasian $(n=24)$ & Japanese $(n=24)$ & Caucasian $(n=24)$ \\
\hline $\mathrm{AUC}_{\text {last }}(\mathrm{ng} \cdot \mathrm{h} / \mathrm{mL})$ & $5.53(241)$ & $3.83(200)$ & $3.42(233)$ & $2.40(385)^{\mathrm{d}}$ \\
\hline $\mathrm{AUC}_{\text {last,normBW }}(\mathrm{ng} \cdot \mathrm{h} \cdot \mathrm{kg} / \mathrm{mL})$ & $320.6(249)$ & $238.0(198)$ & $198.0(249)$ & $147.9(371)^{\mathrm{d}}$ \\
\hline $\mathrm{AUC}_{\text {last,normBW,dose }}(\mathrm{ng} \cdot \mathrm{h} \cdot \mathrm{kg} / \mathrm{mL} / \mathrm{mg})$ & $163.2(209)$ & $118.0(157)$ & $97.5(213)$ & $69.7(359)^{\mathrm{d}}$ \\
\hline$C_{\max }(\mathrm{ng} / \mathrm{mL})$ & $0.41(72)$ & $0.38(68)$ & $0.28(62)$ & $0.26(63)$ \\
\hline$C_{\text {max,normBW }}(\mathrm{ng} \cdot \mathrm{kg} / \mathrm{mL})$ & $23.57(75)$ & $23.38(65)$ & $16.21(67)$ & $16.43(61)$ \\
\hline$C_{\text {max,normBW,dose }}(\mathrm{ng} \cdot \mathrm{kg} / \mathrm{mL} / \mathrm{mg})$ & $12.0(62)$ & $11.59(57)$ & $7.98(59)$ & $7.81(55)$ \\
\hline$t_{\max }^{\mathrm{b}}(\mathrm{h})$ & $24.0(8-60)$ & $24.0(8-60)$ & $25.0(8-60)$ & $24.5(8-60)$ \\
\hline$A_{\mathrm{e}}^{\mathrm{a}}(\mu \mathrm{g})$ & $142.4(56.0)$ & $135.8(58.0)^{\mathrm{c}}$ & $44.1(39.6)$ & $57.4(50.9)^{\mathrm{c}}$ \\
\hline$f_{\mathrm{e}}(\%$ of apparent dose $)$ & $8.17(48.5)$ & $7.11(35.7)^{\mathrm{c}}$ & $3.53(38.8)$ & $4.22(42.9)^{\mathrm{c}}$ \\
\hline
\end{tabular}

Data are expressed as geometric mean (CV\%) unless stated otherwise

$A_{e}$ amount excreted into urine, $A U C_{\text {last }}$ area under the plasma concentration-time curve from time zero to last quantifiable concentration, $C_{m a x}$ maximum plasma concentration, $C V \%$ percentage coefficient of variation, $f_{e}$ fraction excreted into urine, norm $B W$ normalized by body weight, norm $B W$,dose normalized by body weight and dose, $t_{\max }$ time to $C_{\max }$

${ }^{a}$ Arithmetic mean (CV\%)

b Median (range)

c $n=22$

d $n=23$

Japanese subjects [women $108(58 \%)$, men $77(42 \%)$ ]. No AEs were considered serious. The majority of AEs were mild in intensity. Moderate ratings were documented for nausea (six cases), vomiting (four cases), fatigue (three cases), pruritus at the application site (three cases), headache (two cases), dizziness (one case), and insomnia (one case). One case of nausea was rated as severe. All AEs were resolved by the end of the study. Application-site reactions were the most frequently reported AEs and were experienced by $85 \%$ of Caucasian subjects and by all of the Japanese subjects. Erythema was the most common application-site reaction, and occurred in $73 \%$ of Caucasian and $96 \%$ of Japanese subjects. Assessment of skin tolerability showed reddening was generally slight. Evident reddening occurred in two Caucasians and one Japanese subject and marginal (i.e., barely recognizable) application-site edema was observed in 11 subjects in each ethnic group. One male Caucasian subject showed a slight applicationsite edema. Other common AEs included headache [Caucasian 13/26 subjects $(50 \%)$ vs. Japanese 6/24 subjects $(25 \%)]$, fatigue $[9 / 26(35 \%)$ vs. $5 / 24(21 \%)]$, and nausea $[7 / 26(27 \%)$ vs. $8 / 24(33 \%)]$. Vomiting occurred in two subjects in each ethnic group; the two female Caucasian subjects discontinued the study due to nausea and vomiting. All application-site reactions were judged to be highly probably or probably related to the study medication. Other AEs were generally assessed as probably or possibly related. Patch adhesiveness was good; six Caucasian subjects and one Japanese subject showed a detachment of $<20 \%$ and one subject in each ethnic group showed a detachment between 20 and $49 \%$.

No clinically relevant changes were observed in laboratory parameters, physical examination, vital signs, and ECG recordings. Two Caucasian subjects had unusually high plasma concentrations of unconjugated rotigotine; there was, however, no indication of a higher incidence or intensity of AEs.

\section{Discussion}

This study provides a detailed description of the pharmacokinetics of the transdermally applied dopamine agonist rotigotine in healthy Japanese and Caucasian subjects. Mean apparent doses and plasma concentration-time curves for unconjugated rotigotine were comparable between individuals from each ethnic group. No relevant differences in $t_{\max }$ and $t_{1 / 2}$ were observed. Bioavailabilities of unconjugated rotigotine following administration of a single dose were similar in each ethnic group. Point estimates for $\mathrm{AUC}_{\text {last }}$ and $C_{\max }$ included unity, indicating a similar exposure to the active substance. Individual concentration levels for unconjugated rotigotine in plasma showed a high variability between subjects. The variability of the resulting pharmacokinetic parameters $\mathrm{AUC}_{\text {last }}$ and $C_{\max }$ was reduced after normalization by body weight and by apparent dose. Sex differences in $C_{\max }$ and $\mathrm{AUC}_{\text {last }}$ for unconjugated rotigotine were also minimized after body weight normalization. 

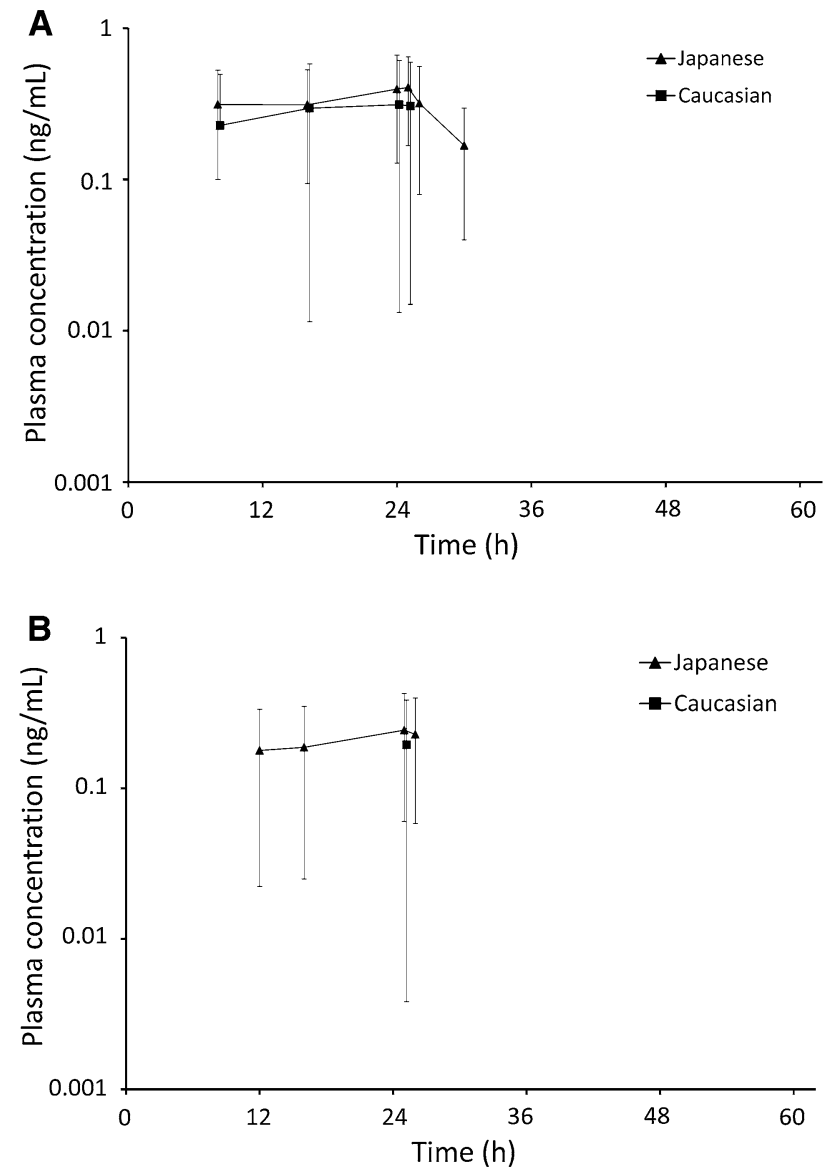

Fig. 3 Mean plasma concentrations (standard deviation) of total despropyl and desthienylethyl rotigotine in Japanese and Caucasian subjects; log-linear scale. a Despropyl rotigotine; b Desthienylethyl rotigotine

Plasma concentrations of total rotigotine differed between ethnic groups. $\mathrm{AUC}_{\text {last }}$ and $C_{\max }$ values were $\geq 20 \%$ higher in Japanese subjects than in Caucasians. Point estimates indicated a statistical difference that was minimized by normalization for body weight, but not by normalization for apparent dose. The very high CL of unchanged rotigotine $(\sim 500 \mathrm{~L} / \mathrm{h}$ in both ethnic groups) indicates extensive metabolism as the main route of elimination. This is in line with an extremely high $V_{\mathrm{d}}$ of about 4,000 L. Differences between $V_{\mathrm{d}}$ values in Japanese and Caucasian subjects may reflect differences in body weight. No differences in the pharmacokinetics of rotigotine, especially elimination via metabolism, can be concluded. Total rotigotine concentrations do not play a role in treatment efficacy but may affect the safety and tolerability of the medication. However, the overall incidence of AEs was similar in both ethnic groups and the high plasma concentrations observed in two Caucasian subjects were not associated with a higher incidence or intensity of AEs.
A

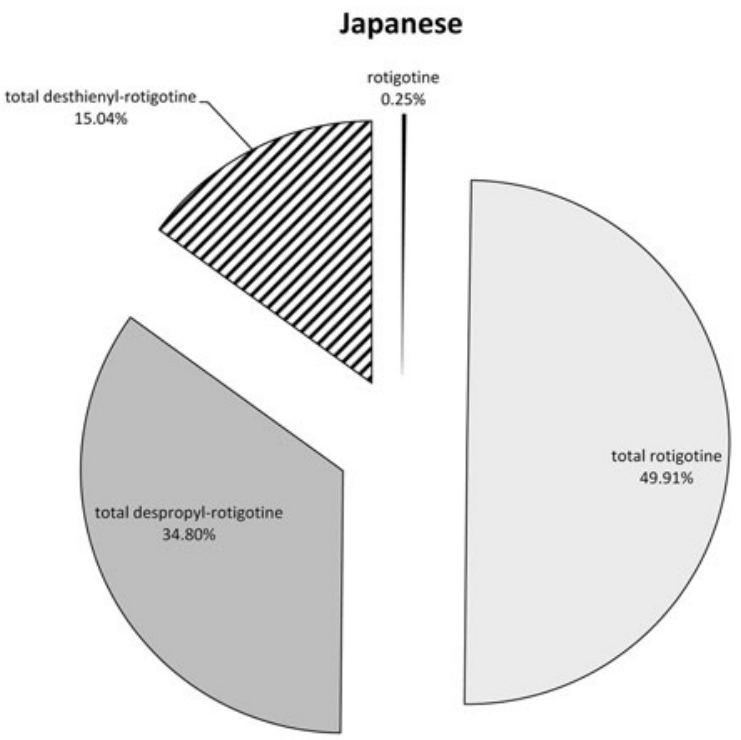

B

Caucasian

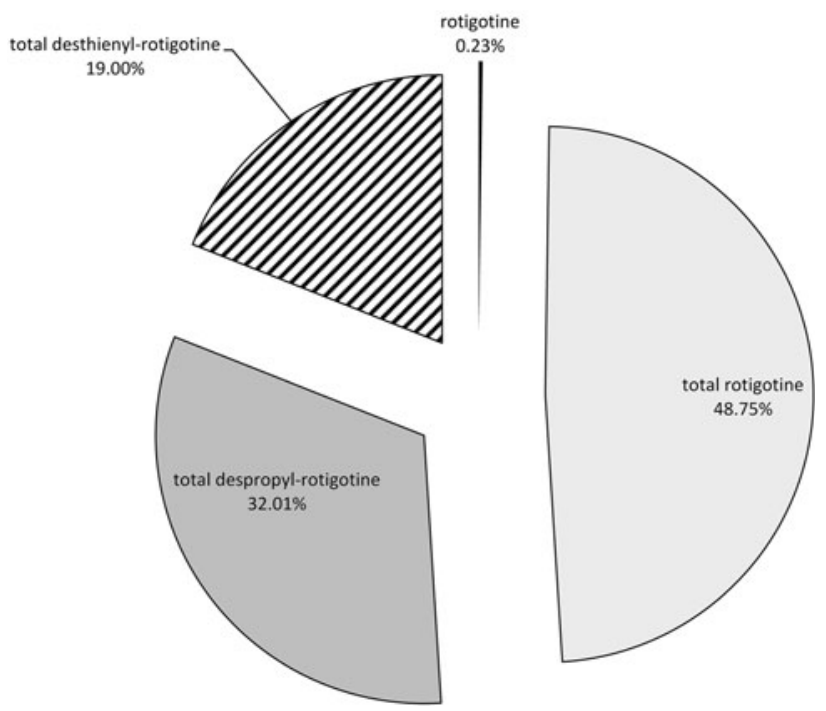

Fig. 4 Profile of renal elimination within $60 \mathrm{~h}$ after patch administration in a Japanese and $\mathbf{b}$ Caucasian subjects

Plasma concentrations of total rotigotine desalkyl metabolites were similar in both ethnic groups; however, they were near or below the LLQ. The low concentrations of metabolites in plasma and the high variability of the values in all subgroups confounded interpretation of the pharmacokinetic parameters. The $\mathrm{CL}_{\mathrm{R}}$ of the active substance was similar in both groups. The $A_{\mathrm{e}}$ was slightly higher for Japanese subjects but accounted for $<1 \%$ of the dose absorbed, indicating a very small contribution of renal excretion to the CL of unconjugated rotigotine. Comparable amounts of total rotigotine and total desalkyl metabolites were excreted into urine. The proportion of total 
despropyl metabolite was more than double that of the desthienylethyl metabolite for both ethnic groups. The metabolic profile of rotigotine observed in our study is in agreement with the results of a pharmacokinetic study in Caucasian subjects [9].

The major isoenzyme involved in rotigotine N-desalkylation, CYP2C19, is known to be differentially expressed in different ethnic groups; around $25 \%$ of Asian individuals and 3-5\% of Caucasians have a poor metabolizer phenotype [25]. However, a study in healthy Caucasian subjects has shown that selective inhibition of CYP2C19 does not affect the steady-state pharmacokinetic profile of rotigotine [26]. Rotigotine dose adjustment may not be necessary in patients who are poor CYP2C19 metabolizers.

Application of a single rotigotine patch was safe and generally well-tolerated. Most AEs were mild in intensity and typical of dopamine agonists (e.g., nausea) or transdermal therapeutics (e.g., mild and transient erythema). Japanese subjects reported a higher incidence of application-site reactions $(100 \mathrm{vs.} 85 \%)$ and a lower incidence of headache ( 25 vs. $50 \%)$ than Caucasians. In the current study, the higher incidence of AEs observed in women than in men ( 58 vs. $42 \%$ ) may be due to sex-related differences in pharmacodynamic response. Patch adhesiveness was good for both ethnic groups; it was, however, better in Japanese than Caucasian subjects.

\section{Conclusion}

The administration of a single patch delivering $2 \mathrm{mg} / 24 \mathrm{~h}$ rotigotine resulted in comparable pharmacokinetic profiles in Japanese and Caucasian subjects. The extent of rotigotine exposure was affected by body weight, but did not appear to be affected by sex. Transdermal rotigotine was safe and generally well-tolerated by both ethnic groups. These findings suggest similar dose requirements for Japanese and Caucasian populations.

\footnotetext{
Acknowledgments This study was funded by UCB Pharma, Monheim am Rhein, Germany. Willi Cawello, Marina Braun, and JanPeer Elshoff are employees of UCB Pharma, Monheim am Rhein, Germany. Seong R. Kim, Junji Ikeda, and Tomoo Funaki are employees of Otsuka Pharmaceutical Co., Ltd., Tokyo, Japan. The authors acknowledge the participation of FOCUS Clinical Drug Development GmbH (Neuss, Germany), which conducted the study. AAI Deutschland GmbH \& Co. KG, Neu-Ulm, Germany performed all bioanalytical work to quantify rotigotine and metabolites in plasma and urine samples. Editorial support was provided by Hannah Carney (Evidence Scientific Solutions, Horsham, UK) and was contracted by UCB Pharma, Brussels, Belgium. The authors also acknowledge Ging-Ging Li, CMPP (Global Publications Manager, Movement \& Sleep Disorders, UCB Pharma, Brussels, Belgium) for publication coordination. All costs associated with the development and the publishing of the present manuscript were met by the sponsor.
}

Open Access This article is distributed under the terms of the Creative Commons Attribution Noncommercial License which permits any noncommercial use, distribution, and reproduction in any medium, provided the original author(s) and the source are credited.

\section{References}

1. Schapira AH. Science, medicine, and the future: Parkinson's disease. BMJ. 1999;318:311-4.

2. Rascol O, Goetz C, Koller W, Poewe W, Sampaio C. Treatment interventions for Parkinson's disease: an evidence based assessment. Lancet. 2002;359:1589-98.

3. Olanow CW, Jankovic J. Neuroprotective therapy in Parkinson's disease and motor complications: a search for a pathogenesistargeted, disease-modifying strategy. Mov Disord. 2005;20: S3-10.

4. Olanow CW, Watts RL, Koller WC. An algorithm (decision tree) for the management of Parkinson's disease (2001): treatment guidelines. Neurology. 2001;56:S1-88.

5. Bhatia K, Brooks DJ, Burn DJ, Clarke CE, Grosset DG, MacMahon DG, et al. Updated guidelines for the management of Parkinson's disease. Hosp Med. 2001;62:456-70.

6. Scholz H, Trenkwalder C, Kohnen R, Riemann D, Kriston L, Hornyak M. Dopamine agonists for restless legs syndrome. Cochrane Database Syst Rev. 2011;(3):CD006009.

7. Jenner P. A novel dopamine agonist for the transdermal treatment of Parkinson's disease. Neurology. 2005;65:S3-5.

8. Pfeiffer RF. A promising new technology for Parkinson's disease. Neurology. 2005;65:S6-10.

9. Cawello W, Wolff HM, Meuling WJ, Horstmann R, Braun M. Transdermal administration of radiolabelled [14C]rotigotine by a patch formulation: a mass balance trial. Clin Pharmacokinet. 2007;46:851-7.

10. Cawello W, Braun M, Boekens H. Absorption, disposition, metabolic fate, and elimination of the dopamine agonist rotigotine in man: administration by intravenous infusion or transdermal delivery. Drug Metab Dispos. 2009;37:2055-60.

11. Cawello W, Ahrweiler S, Sulowicz W, Szymczakiewicz-Multanowska A, Braun M. Single dose pharmacokinetics of the transdermal rotigotine patch in patients with impaired renal function. Br J Clin Pharmacol. 2012;73:46-54.

12. Parkinson Study Group. A controlled trial of rotigotine monotherapy in early Parkinson's disease. Arch Neurol. 2003;60: 1721-8.

13. Watts RL, Jankovic J, Waters C, Rajput A, Boroojerdi B, Rao J. Randomized, blind, controlled trial of transdermal rotigotine in early Parkinson disease. Neurology. 2007;68:272-6.

14. Giladi N, Boroojerdi B, Korczyn AD, Burn DJ, Clarke CE, Schapira AH. Rotigotine transdermal patch in early Parkinson's disease: a randomized, double-blind, controlled study versus placebo and ropinirole. Mov Disord. 2007;22:2398-404.

15. Poewe WH, Rascol O, Quinn N, Tolosa E, Oertel WH, Martignoni E, et al. Efficacy of pramipexole and transdermal rotigotine in advanced Parkinson's disease: a double-blind, double-dummy, randomised controlled trial. Lancet Neurol. 2007;6:513-20.

16. LeWitt PA, Lyons KE, Pahwa R. Advanced Parkinson disease treated with rotigotine transdermal system: PREFER study. Neurology. 2007;68:1262-7.

17. Trenkwalder C, Kies B, Rudzinska M, Fine J, Nikl J, Honczarenko $\mathrm{K}$, et al. Rotigotine effects on early morning motor function and sleep in Parkinson's disease: a double-blind, randomized, placebo-controlled study (RECOVER). Mov Disord. 2011;26:90-9. 
18. Oertel WH, Benes H, Garcia-Borreguero D, Geisler P, Hogl B, Saletu B, et al. Efficacy of rotigotine transdermal system in severe restless legs syndrome: a randomized, double-blind, placebo-controlled, six-week dose-finding trial in Europe. Sleep Med. 2008;9:228-39.

19. Trenkwalder C, Benes H, Poewe W, Oertel WH, Garcia-Borreguero D, de Weerd AW, et al. Efficacy of rotigotine for treatment of moderate-to-severe restless legs syndrome: a randomised, double-blind, placebo-controlled trial. Lancet Neurol. 2008;7:595-604.

20. Hening WA, Allen RP, Ondo WG, Walters AS, Winkelman JW, Becker $P$, et al. Rotigotine improves restless legs syndrome: a 6-month randomized, double-blind, placebo-controlled trial in the United States. Mov Disord. 2010;25:1675-83.

21. International Conference on Harmonisation; guidance on ethnic factors in the acceptability of foreign clinical data; availabilityFDA. Notice. Fed Regist. 1998;63:31790-6.
22. Chen ML. Ethnic or racial differences revisited: impact of dosage regimen and dosage form on pharmacokinetics and pharmacodynamics. Clin Pharmacokinet. 2006;45:957-64.

23. Evidente VG, Esteban RP, Domingo FM, Carbajal LO, Parazo MA. Piribedil as an adjunct to levodopa in advanced Parkinson's disease: the Asian experience. Parkinsonism Relat Disord. 2003;10:117-21.

24. Hattori N. Appropriate dosing of pergolide in monotherapy and adjunctive therapy in Parkinson's disease. Curr Opin Neurol. 2003;16(Suppl 1):S21-5.

25. Rodrigues AD, Rushmore TH. Cytochrome P450 pharmacogenetics in drug development: in vitro studies and clinical consequences. Curr Drug Metab. 2002;3:289-309.

26. Elshoff J-P, Cawello W, Andreas J-O, Braun M. No influence of the CYP2C19-selective inhibitor, omeprazole, on the pharmacokinetics of the dopamine receptor agonist rotigotine. Clin Pharmacol Drug Dev. In Press. 